\title{
Can Help for Patients Be Too Expensive? Ethical Considerations and End-Stage Lung Disease
}

\author{
Giovanni Maio \\ Institute for Medical Ethics and History of Medicine, University of Freiburg, Freiburg i.Br., Germany
}

\author{
Key Words \\ Medical ethics $\cdot$ Cost containment $\cdot$ Rationing . \\ Duty to help $\cdot$ Charity
}

\begin{abstract}
The treatment of patients with end-stage lung disease is very expensive. In an era of cost containment, the physician could be forced to restrict his therapy in order to spend less. But does the physician really have the right to restrict a reasonable therapy for economic reasons? It is argued that the mission of medicine is to help people in need and that any confidence is shaken if the physician is forced to be both physician and gatekeeper at the same time. It is argued that medicine as a central form of care will only be able to survive if it has the chance to remain a free profession, a profession which has the liberty to help each individual patient even if this help is expensive. However, it remains a duty of the physician to accept limits and to learn that for a good death it is necessary to be honest and to talk early enough about the possibilities of palliative care. Copyright $\odot 2011$ S. Karger AG, Basel
\end{abstract}

Previous articles in this series: 1. Boehler A, Herth FJF: Palliation in lung diseases - facing the challenge and new hope: introduction. Respiration 2011;82:109-110. 2. Gompelmann D, Eberhardt R, Herth FJF: Advanced malignant lung disease: what the specialist can offer. Respiration 2011;82:111-123. 3. Kreuter M, Herth FJF: Supportive and palliative care of advanced nonmalignant lung disease. Respiration 2011;82:307-316.

\section{KARGER \\ Fax +4161306 1234 \\ E-Mail karger@karger.ch}

www.karger.com
(C) 2011 S. Karger AG, Basel

$0025-7931 / 11 / 0825-0395 \$ 38.00 / 0$

Accessible online at:

www.karger.com/res
Treating patients with advanced lung disease has very much to do with medical ethics, because these patients are vulnerable, distressed and need help much more than mere technique. At the end of life it has to be asked whether the technological imperative is still the adequate treatment. We have to ask when technological intervention has to be replaced by palliative care. However, the decision to leave the invasive strategy must not to be taken too easily; if, for example, the treatment of lung cancer with chemotherapeutics becomes very expensive, there may be a temptation to stop this therapy not only for lack of effectiveness but also for lack of resources. Therefore, such decisions have to be taken very carefully. Patients with end-stage lung disease need more than technique and specific drugs $[1,2]$. But how much technique and chemotherapeutics do they need? And how are we to decide when these treatments are so expensive that a dozen other patients could be treated with these resources spent on new therapeutics?

\section{Medicine Must Not Waste Resources}

For patients with advanced lung disease, medical treatment is very expensive. We could say that it is not worthwhile spending so much money only for one group of patients, because we will lack this money in other fields of medicine. Because money is always short and because everything we are doing in medicine is of particular im- 
portance, we have an ethical duty to spend the money in a reasonable way. We cannot say that as physicians we do not have to care about money, because the money spent in medicine comes from employees and employers who have a right to know that their money is well invested and not wasted. Thus, the question is whether it is a waste of money if we spend a lot of funds 'only' for end-stage chronic disease. To answer this question we have to know what 'waste' means. It is a waste of money, we can be sure, when we offer futile treatment, i.e. when we treat without expecting any benefit. But what treatment is without benefit? For example, treatment in lung cancer is often without benefit, because the individual patient is a non-responder. Thus, it can lead to less waste if - via pharmacogenomics - we are able to say with more certainty whether the specific therapeutics will be effective. Spending money in order to obtain an individualized therapy can in no way be a waste. Even if these drugs are much more expensive than the classic ones, we can say from an ethical point of view that they can be a great progress for patients, because we can spare them the inconvenience of ineffective therapies. The question remains whether pharmacogenomics really leads to such medicaments with such predictions, and above all how sure can these predictions be, how valid are they and how helpful are they for the single patient? We can resume that individualized medicine is no waste as long as it helps us to prevent ineffective therapies [3]. Therefore, society has the duty to make these new drugs affordable, because otherwise we would neglect particularly those patients who are most vulnerable and in special need.

\section{The Primary Goal of Medicine Is to Help and Not to Count}

Up to this point we have seen that there is a duty for medicine to think about efficiency, because the aspect of a reasonable expenditure is part of medical ethics. However, this is true only to a certain degree, because, on the other hand, there are limits to economic reasoning in medicine. We have to realize that there are some messages which a physician will be unable to communicate to patients. The physician would be burdened with such an unethical message if he were forced to admit that he is able to help the patient but prefers not to do so because the possible help would be too expensive for him and for the hospital. No patient is willing to accept such a message from his physician, and if a physician made such a suggestion he would not act as a physician: because he has become a physician in order to help, and a physician who says that he could help but decides not to do so, would lose his credibility. Where relevant help is possible, especially the physician has a duty to help, and society has a duty to make this help possible. Where cost containment policies are so restrictive that the physician has no possibility to offer a therapy which is effective and needed, such a situation cannot be accepted by the physician, because this makes medical treatment impossible and also hinders the physician in making genuine medical choices. A physician who is forced to look only at money and not at the question of how to help his patients can no longer be a physician. And such a physician would lose the trust of society. Thus, it is a duty of the physicians to reject rationing at the bedside, because this would not be accepted by society [4].

\section{Rationing Choices Must Not Be Imposed on Physicians}

'Rationing' means that a physician decides not to give a much needed therapy for economic reasons. A physician should not make such decisions on his own because he may endanger his role as a physician, which is to help and not to distribute. If therapies are too expensive, it must not be the decision of the physician to refuse this therapy, but it has to be a political and democratic decision that society cannot afford this therapy or another. In Germany we have IQWiG and in Great Britain we have NICE which assume this role. But if the politicians proclaim that the patients of our days have the right to get all treatments they want, and if the same politicians restrict the financial basis of hospitals and medical offices, this leads to a conflict of interests for the physician. He will be forced to make rationing choices if he does not want to risk his financial basis. Such a situation is not acceptable, because it leads to the corruption of medicine. It leads to physicians who are forced to abandon their role of a fiduciary for the patient and to make decisions which are not motivated by genuine medical reasoning but by the reasoning of a businessman.

\section{Economics Has to Serve Medicine and Not Vice Versa}

So we come to the central question. What really is the relationship between economics and medicine? First of all, we have to realize that economic considerations are not contrary to good medicine but are part of it. Economic 
considerations are part of ethical considerations, and medicine needs economic know-how. But this economic knowhow has to be embedded in medical aims. That means economic considerations have to be seen as supporting medicine in order to attain the medical aims at a lower cost and without waste. Economy is part of medicine because it helps medicine to attain medical aims in an efficient manner. Economy has to help medicine, but nowadays economy no longer has such an auxiliary function. Rather economy has become the central aim in hospitals, and it is medicine itself which has become the auxiliary discipline which helps economy to realize economic aims. The challenge of economy today lies in the fact that medicine is no longer concentrated on medical aims and needs but only on economic interests. If a hospital is offering only those therapies which are profitable, we can no longer call it a part of medicine. It has become a part of a business company, but not part of a social practice as medicine has to be.

Economic considerations are very important for medicine, but they must not override everything else because medicine has another task, another duty, another mission than to invest money. The mission of medicine is to help people in need, to assist those who cannot help themselves. And so we have to realize that for medicine there are some values which are more important than economic considerations. For example the value of life itself: pricing life is a very problematic attitude for medicine. It was the German philosopher Immanuel Kant who made clear that human life has no price but dignity [5]. That means that if we are able to save life, we must not begin to count the price of saving life, because life has no price. We cannot tell the relatives of a patient who died that we refrained from saving his life because it would have been too expensive. Medicine has to save life and if medicine can do it, it has to help and not to count.

\section{Is It Really 'Help' to Prolong Life for Two Weeks?}

The question remains: is it really all life which has to be saved? What about life at the end of life? It becomes clear that saving life is not the only duty for physicians. The next duty for physicians is to respect the individuality of every patient, to look at the uniqueness of every patient. If a patient at the end of his life wants to die without medical interventions we have to respect this, even if life could have been prolonged for some weeks. But if a patient wants us to help him to live longer even with interventions, we have to respect this too - provided that the medical therapies are not futile. We have to take into con- sideration the individual needs of patients. Medicine must not waste resources, we have said. And medicine must not offer futile therapies, because with these therapies medicine cannot help and because these are a waste of resources. Nevertheless, the primary reason for not offering futile therapies is the duty not to harm patients. And so we come to lung cancer patients.

What is help for lung cancer patients? Where we can save life, it is help without doubt. But where we prolong life for an average of 2 or 3 weeks, it is debatable whether this is really help. It can be if the patient chooses this way. But how does the patient decide? In general he is following the suggestions of the physicians. Therefore, the physician has a great responsibility especially at the end of life, because his words will be crucial for the patient's decisions. It is up to him to reflect on what could be helpful for his patients. It seems easier for the physician to offer a further therapy even if he knows that the therapy will not change a lot. But when therapy will not change a lot, can we really call such a treatment 'therapy'? It is much more difficult to tell the patient that all therapies available will not change a lot and that palliative care would be best for him. To offer such a plan is difficult, but often, very often, it is necessary, and often, too often, such an offer is avoided because some physicians prefer ordering medication to talking about death. Where medications are ordered because the physician feels uneasy talking about death, it is not only a waste of money in medicine but it is above all a waste of a chance to have a good, wellprepared and calm death.

\section{Medicine Has to Learn to Accept Limits}

What is waste in medicine? It is a waste to start therapies which are futile. But it is also a waste to offer chemotherapeutics where palliative care would be the better strategy. This makes it clear that every physician has to think about the real aim of medicine and has the responsibility to accept the limits of chemotherapy. Often therapies in medicine are offered as progress where no real progress is at hand. Quite often, when a conflict between ethics and economics is claimed, it is rather a false antinomy, because in some cases the limitation of the use of a given technology and specific drugs that economics demands would also be in the patient's best interest. There are often situations in which the use of therapeutics is most probably unsuccessful. When the benefit is likely to be only marginal, it does not seem justified to recommend such a therapy which is not only expensive, but also 
distressing. The problem is, however, that physicians often disagree about which patient can really benefit and which not. Yet, we have to realize that the way health care is organized and funded produces false incentives, because those physicians who make an abundant use of technology are rewarded and those who plead for a more palliative care have to fear less support for their strategy.

\section{Ethical Limits of Cost-Benefit Assessments}

However, we cannot solve these problems with mere cost-benefit assessments. From an ethical point of view cost-benefit assessments are very dangerous, because they are too abstract and tend to disadvantage the patients who are least well off. In order to make a good clinical decision, we cannot only rely on numbers [2]. Of course, we have the duty to know the statistical numbers, to know the evidence, to know the costs, but we have, above all, to take into consideration the concrete situation of each single patient. We have to look at the individual circumstances of the patient, at the patient as a singular person at a singular stage of a singular life. All this singularity can hardly be put into a medically sound rule, because such a rule would be made for a standard type of patient, not for the patient as an individual. Too often it is forgotten that the core of medicine is the ability to make individual decisions for the individual patient. If you take cost-benefit assessments, you have to abstract from the patient and you have to decide on a category rather than on a person. Cost containment for patients with chronic lung disease is not possible without making - rather implicit - decisions on what good life is, what good death is, what quality of life as a whole really is. Yet, there is no arithmetic to count quality of life because every patient has his own preferences, his own idea of a good life. That is the problem of cost-benefit analysis in dealing with end-stage chronic disease.

\section{From a Relationship of Trust to One of Contract?}

From an ethical point of view, it is very problematic to see the physician as a gatekeeper, because there are a lot of conflicting interests between a person who wants to help and a person who has to distribute money. The physician has the duty to help, and in order to do this in a sound way he has to remain a physician. Being a physician means two things: it means knowing what to do to help people in need of help, and it means having only one motivation - to offer help whenever it is possible. When the physician becomes an agent hired by investors who themselves have no human motivation to help but only an egoistic motivation to do good business, this situation becomes dangerous in terms of the ethics of the physician. It is dangerous because, in this case, the physician begins to practice marketplace ethics and not those of medicine. He no longer considers his relationship with the patient as one of trust, but as a relationship of contract and of trade-off. Ethics then become not a matter of moral obligations or virtue, but only one of legality and tradeoff. The concepts of business and law replace those of virtue and altruistic devotion to the patient. In the end, such 'ethics of businessmen' will lead to an exploitation of the patient, because patients are not - as customers - the strong partners of a contract, rather they are vulnerable, in need and often desperate. Therefore, patients are not in a strong position and have to be protected from exploitation. The natural protector of the patient has to be the physician himself, because being the advocate of the patient is the core of the professional duty of a physician. The physician is a person who makes a promise, the promise to be there for the patient. If the physician now becomes a businessman, this promise is no longer valid. The businessman does not make any other promise than not to act against the contract. But the main need of the patient, his longing for a human person whom he can trust, cannot become part of a contract.

\section{The Physician as a Double Agent?}

The patient is not a customer but a dependent suffering human being who has no choice but to trust medicine. This trust can be eroded if medicine becomes more business than support. Incentives that reward physicians for limiting the prescriptions create conflicts of interest and undermine the patient's trust in the humanity of medicine. More and more patients fear that necessary treatments are withheld, they fear that physicians may more and more be acting in their own interests rather than in the interest of their patients. That is the central problem of gatekeeping: physicians are no longer the advocates of patients, but they are forced to serve the patient and the health care organization at the same time. The introduction of such a double agency for the physician means an introduction of a new culture of suspiciousness, a new culture of distrust, because the patient always has to fear that his physician could decide not in his favor but in the interests of the hospital. 


\section{Medicine Is Not a Business but Charity}

What are my conclusions? Even in our days, medicine still has to define itself above all as a discipline of help. As such, medicine has the duty to assist patients. But medicine has also the duty to avoid waste, because if it wastes resources these will be missing elsewhere in medicine. What waste is cannot be defined easily, because it depends on the concept of a good life of every patient. Therefore, we should not leave the definition of waste to economics, because economics does not know anything about what is good for the single patient. It is rather a duty of every physician to decide what is wasteful and what is not. It is his duty not to waste resources, because if he does so, it will be economics (and politics) forcing him to make decisions which will be good for economics but not always good for patients. It is therefore a moral duty of physicians to make reasonable suggestions and decisions. And physicians have the duty to always keep in mind the limits of feasibility. Therefore, it should be an internal duty of medicine to talk about limits and to find internal rules in order to prevent waste. Physicians cannot delegate this reasoning to economics because economics lacks the necessary knowledge of what is a medical benefit and what is not. Especially in our time, medicine has to fight for the core of its identity. Medicine can only remain a profession if it succeeds in preserving the liberty of doing what it demands and not what economics demands. This liberty is not a privilege but a duty, a duty necessary for future patients. Therefore, I should say that medicine as a central form of care for patients will only be able to survive if it has the chance to remain a free profession, a profession which has the liberty to help each individual patient even if this help is expensive. This freedom to say yes even to an expensive therapy is a central moral imperative, and no entrepreneur has the right to abolish this liberty, because this would also be the abolishment of medicine as charity.

\section{References}

1 Maio G: Mittelpunkt Mensch - Ethik in der Medizin. Stuttgart, Schattauer, 2011.

2 Simonds AK: Ethics and decision making in end stage lung disease. Thorax 2003;58:272277.

3 Sulmasy DP: Cancer care, money, and the value of life: whose justice? Which rationality? J Clin Oncol 2007;25:217-222.
4 Bernardi A, Jirillo A, Pegoraro R, Bonavina MG: Allocation of public sources in oncology: which role can ethics play? Ann Oncol 2007;18:1129-1131.

5 Kant I: Grounding for the Metaphysics of Morals, Ak 435. Indianapolis, Hackett, 1981. 